\title{
INFLUENCIA DO PROCESSO DE SECAGEM SOBRE A MASSA ESPECÍFICA APARENTE, MASSA ESPECÍFICA UNITÁRIA E POROSIDADE DE MILHO-PIPOCA ${ }^{1}$
}

\author{
Solenir Ruffato², Paulo Cesar Corrêa ${ }^{3}$, José Helvecio Martins ${ }^{4}$, \\ Bárbara Heliodora Machado Mantovani ${ }^{5}$ e Jadir Nogueira da Silva ${ }^{6}$
}

\begin{abstract}
RESUMO
Vários fatores afetam a qualidade do milho-pipoca, dentre os quais se encontram as propriedades físicas, como tamanho dos grãos e massa específica unitária e aparente e porosidade da massa granular. Para se avaliar a influência do processo de secagem sobre a massa específica e a porosidade da massa granular, teve-se por objetivo, com este trabalho, determinar as propriedades físicas para duas cultivares de milho-pipoca, em função do teor de umidade. Para obtenção dos resultados foram utilizados grãos de milho-pipoca das cultivares Zélia e CMS 43, submetidas ao processo de secagem a $\quad 40{ }^{\circ} \mathrm{C}$; simultaneamente, determinou-se a massa específica aparente e real de ambas as cultivares, a vários níveis de teor de umidade. A faixa de teor de umidade utilizada foi de 10,2 a $17,2 \%$ b.u. e 10,4 a $19,4 \%$ b.u., respectivamente, para as cultivares Zélia e CMS 43 e os valores médios obtidos foram: 768 e 767

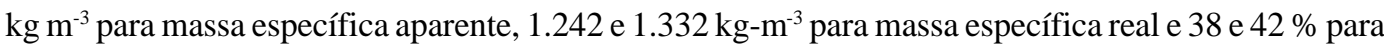
porosidade da massa granular. O comportamento das propriedades físicas, em relação à influência do processo de secagem, apresentou características semelhantes às de outras variedades de milho.
\end{abstract}

Palavras-chave: milho-pipoca, secagem, propriedades físicas, teor de umidade

\section{INFLUENCE OF THE DRYING PROCESS ON UNIT DENSITY, BULK DENSITY AND POROSITY OF POPCORN}

\footnotetext{
ABSTRACT

Several factors may affect the popcorn quality, physical properties such as grain size, porosity and density being the most important. The objective of this research was to evaluate effects of the drying process on these physical properties for two popcorn varieties as a function of the moisture content. The popcorn grains from Zélia and CMS 43 varieties were utilized in this study and subjected to the drying process at $40^{\circ} \mathrm{C}$. Simultaneously, the bulk and unit density for both varieties at several moisture contents were determined. The range of moisture content utilized was $10.2-17.2 \%$ w.b. and $10,4-19,4 \%$ w.b. for

${ }^{1}$ Extraído da Tese de Mestrado apresentada pelo primeiro autor à UFV, Viçosa, MG

${ }^{2}$ M.Sc., Depto. de Engenharia Agrícola, UFV, CEP 365701-000 Viçosa, MG, Fone (031) 899 2729, Fax: (031) 8992735

E-mail: sruffato@alunos.ufv.br

${ }^{3}$ D.S., Depto. de Engenharia Agrícola, UFV. Bolsista do CNPq, E-mail: copace@ mail.ufv.br

${ }^{4}$ Ph.D., Depto. de Engenharia Agrícola, UFV. Bolsista do CNPq, E-mail: jmartins@ mail.ufv.br

${ }^{5}$ Ph.D., EMBRAPA/Centro Nacional de Pesquisa de Milho e Sorgo, Sete Lagoas, MG

${ }^{6}$ Ph.D., Depto. de Engenharia Agrícola, UFV. Bolsista do CNPq, E-mail: jadir@ mail.ufv.br
} 
the varieties Zélia and CMS 43, respectively. The meam values obtained for bulk density were: 768 and $767 \mathrm{~kg} \mathrm{~m}^{-3}$; for unity density 1,242 and $1,332 \mathrm{~kg} \mathrm{~m}^{-3}$, and for porosity, 38 and $42 \%$ for the Zélia and CMS 43 varieties, respectively. The behavior of the physical properties, in relation to the influence of the drying process, was similar to other varieties of corn.

Key words: popcorn, drying, physical properties, moisture content

\section{INTRODUÇÃO}

A tecnologia de produção do milho-pipoca e processamento industrial são aspectos que vêm despertando o interesse de diversos pesquisadores, devido à expansão do cultivo do milhopipoca em vários Estados do Brasil, em razão do crescente consumo de pipoca.

A chegada de pipocas importadas dos Estados Unidos e, também, o lançamento recente de variedades nacionais para uso em fornos de microondas, têm contribuído significativamente para a expansão deste mercado. Como é o mercado que determina os rumos da agricultura, o cultivo do milho-pipoca tende a expandir-se, contando com alguns fatores favoráveis: a cultura pode ser totalmente mecanizada, é pouco susceptível ao ataque de pragas e doenças no campo e seus preços não são controlados pelo governo; além disso, seu preço tem sido, no mínimo, três vezes superior ao do milho comum (Informativo Coopercitrus, 1993). Em razão disso, a qualidade do milho-pipoca tem melhorado gradativamente nos últimos anos, embora não existam padrões oficiais de qualidade para este nem para a maioria dos produtos vegetais produzidos no Brasil.

Segundo Pacheco et al. (1996) o milho-pipoca, devido ao tamanho reduzido e à dureza de suas sementes, apresenta características muito peculiares de utilização, que devem ser consideradas pelos produtores de sementes, visto a dificuldade do aproveitamento das sobras de comercialização de sementes devendo, quase exclusivamente, serem utilizadas para o consumo humano, na forma de pipoca. Muitos produtores já perceberam este fato e resolveram tornar sua atividade de duplo propósito, ou seja, comercializam os grãos maiores como sementes e os menores (sobras de sementes que não podem ser tratadas) como grãos.

Somente na metade deste século foi reconhecida a importância comercial e industrial do milho-pipoca como resultado de uma grande procura do produto, estimulando a sua produção em larga escala; sob o ponto de vista comercial, o fator de maior importância é a sua capacidade de expansão e o produto obtido na expansão é vendido na base de volume e a alta expansão eleva os lucros.

A capacidade de expansão (CE) é calculada pela relação entre o volume de pipoca obtido e o volume de grãos utilizados e constitui o principal parâmetro de qualidade do milho-pipoca. A expansão ocorre devido à resistência do pericarpo associado ao teor de umidade e teor de óleo do grão; quando submetido ao calor, o amido do milho-pipoca expande-se, aumentando gradualmente a pressão interna do grão, até que ocorre a explosão (Silva, 1993).

A CE do milho-pipoca está condicionada tanto a fatores genéticos como extragenéticos, como as condições de desenvolvimento em campo, condições de colheita, préprocessamento e armazenamento.
A massa e o teor de umidade são propriedades que ajudam a estabelecer um padrão de qualidade, pois influenciam diretamente no volume de expansão.

Algumas variedades podem ser colhidas com teor de umidade de até $30 \%$ b.u., porém este teor de umidade é inadequado para que o produto seja armazenado com segurança, necessitando passar pelo processo de secagem, cuja operação possibilita, portanto, que a colheita seja realizada antecipadamente, evitando danos que ocorrem no campo devido às condições climáticas, a ataques de insetos e microrganismos contribuindo, desta forma, para a manutenção da qualidade do produto.

White et al. (1980) colheram milho-pipoca com teor de umidade de 17 a $27 \%$ b.u., submeteram-no a um processo de secagem a temperaturas de $38,40,60,71 \mathrm{e} 82^{\circ} \mathrm{C}$, com velocidade mínima do ar de $0,25 \mathrm{~m} \mathrm{~s}^{-1}$, e avaliaram sua capacidade de expansão, em que os resultados mostraram que o volume de expansão é afetado pelo teor de umidade do produto na ocasião da colheita e/ou temperatura do ar de secagem.

Bemis \& Huelsen (1955) citados por White et al. (1980) estudaram a formação de trincas no endosperma do milhopipoca, relacionando-as com a secagem e concluíram que a percentagem de grãos com trincas está relacionada à taxa de secagem do milho-pipoca (em espiga) e é independente do teor de umidade final.

Dalbello \& Biagi (1996) trabalhando com milho-pipoca da variedade Mays Forte 1001, verificaram que não havia justificativa para a classificação do milho-pipoca por tamanho, pois a CE foi estatisticamente igual para os resultados obtidos tanto com grãos maiores e iguais à peneira 15 , quanto com os grãos menores; observaram, também, que a $\mathrm{CE}$ aumenta com o aumento da massa específica e que a melhor CE foi obtida para teores de umidade na faixa de 10 a $11 \%$ b.u.

Lyerly (1942) observou que o volume de expansão do milhopipoca está correlacionado ao tamanho e à forma dos grãos, em que grãos pequenos, curtos e arredondados, apresentaram maior volume de expansão.

Segundo Song \& Eckahoff (1994) o tamanho do grão e o genótipo afetam significativamente o volume de expansão e o número de grãos estourados. Conforme esses autores, o teor de umidade para uma expansão máxima varia de acordo com o tamanho dos grãos, em que grãos pequenos requerem teor de umidade ligeiramente mais alto, para realizar a máxima expansão.

Portanto, pela literatura encontrada pode-se inferir que a umidade dos grãos, as condições do pericarpo e endosperma, o método de secagem e propriedades físicas (como tamanho do grão e massa específica) dentre outros, são os principais fatores que afetam a capacidade de expansão do milho-pipoca.

Por não se haver encontrado, na literatura consultada, informações a respeito das propriedades físicas referentes às cultivares de milho-pipoca Zélia e CMS 43, o objetivo deste trabalho foi determinar as massas específicas unitária e aparente e a porosidade da massa granular, em função do teor de umidade para essas cultivares. 


\section{MATERIAL E MÉTODOS}

Este trabalho foi desenvolvido no Laboratório de Armazenamento e Pré-Processamento de Produtos Vegetais, do Departamento de Engenharia Agrícola da Universidade Federal de Viçosa.

Foram utilizados grãos de milho-pipoca (Zea mays) das cultivares Zélia e CMS 43. A cultivar Zélia é um híbrido triplo, de grãos de cor amarela, pequenos e arredondados, enquanto a CMS 43 é uma variedade ainda em processo de melhoramento genético, de grãos de cor branca, maiores e mais alongados que os da cultivar Zélia.

Foram determinadas as seguintes propriedades físicas: massa específica aparente, massa específica unitária e porosidade da massa granular.

A massa específica aparente foi determinada com o auxílio de uma balança de peso hectolítrico, com capacidade de $0,25 \mathrm{~L}$, o volume dos grãos foi determinado pelo método do deslocamento de líquido (óleo vegetal) utilizando-se uma bureta de $50 \mathrm{~mL}$ e as amostras foram compostas de 100 grãos.

Essas propriedades foram determinadas, acompanhando-se o processo de secagem para o qual se utilizou um secador de laboratório em camada fina, com controle de temperatura e vazão do ar; a velocidade do ar de secagem foi mantida constante em $1 \mathrm{~m} \mathrm{~s}^{-1}$ e monitorada por um anemômetro digital de lâminas rotativas, enquanto o fluxo de ar era proporcionado por um ventilador axial que conduzia o ar até o plênum, onde fluía, através de três câmaras individualizadas com bandejas de fundo telado e removíveis. A temperatura do ar de secagem utilizada foi de $40^{\circ} \mathrm{C}$, os intervalos de teor de umidade final foram de 10,2 a $17,2 \%$ e 10,4 a 19,4\%, para as cultivares Zélia e CMS 43, respectivamente. Para cada avaliação da massa específica aparente e da massa específica unitária foram realizadas três repetições e a porosidade da massa granular calculada utilizandose a equação:

em que

$$
\varepsilon=\left[1-\left(\rho_{\mathrm{Ap}} / \rho_{\mathrm{Un}}\right)\right]
$$

$\varepsilon \quad$ - porosidade da massa granular $(\%)$

$\rho_{\text {Ap }}$ - massa específica aparente $\left(\mathrm{kg} \mathrm{m}^{-3}\right)$

$\rho_{\text {Un }}$ - massa específica unitária $\left(\mathrm{kg} \mathrm{m}^{-3}\right)$

\section{RESULTADOS E DISCUSSÃO}

Os resultados de massa específica aparente, massa específica unitária e porosidade da massa granular, obtidos para a cultivar Zélia e CMS 43, variando o teor de umidade da amostra, são apresentados na Tabela 1.

Analisando-se os valores apresentados na Tabela 1, observa-se que a massa específica aparente e a massa específica unitária diminuem com o aumento do teor de umidade do produto, enquanto a porosidade da massa granular aumenta. Este comportamento está de acordo com o encontrado por Chung \& Converse (1969) e por Gustafson \& Hall (1972) seguindo as mesmas características da maioria dos produtos agrícolas.
Tabela 1 - Massa específica aparente, massa específica unitária e porosidade da massa granular do milho-pipoca, cultivar Zélia, para diferentes teores de umidade da amostra

\begin{tabular}{cccc}
\hline $\begin{array}{c}\text { Teor de umidade } \\
\text { (\% b.u. })\end{array}$ & $\begin{array}{c}\rho_{\text {Ap }} \\
\left(\mathrm{kg} \mathrm{m}^{-3}\right)\end{array}$ & $\begin{array}{c}\rho_{\text {Un }} \\
\left(\mathrm{kg} \mathrm{m}^{-3}\right)\end{array}$ & $\begin{array}{c}\varepsilon \\
(\%)\end{array}$ \\
\hline \multicolumn{4}{c}{ Cultivar Zélia } \\
17,2 & 750,64 & $1.231,40$ & 39,04 \\
14,2 & 764,87 & $1.239,00$ & 38,27 \\
11,7 & 769,00 & $1.242,10$ & 38,09 \\
11,5 & 771,97 & $1.242,70$ & 37,88 \\
10,2 & 783,07 & $1.255,60$ & 37,63 \\
& Cultivar CMS 43 & \\
19,4 & 725,45 & $1.289,80$ & 43,76 \\
14,4 & 767,65 & $1.330,80$ & 42,32 \\
12,4 & 774,12 & $1.338,70$ & 42,17 \\
11,5 & 777,17 & $1.343,50$ & 42,15 \\
10,4 & 790,03 & $1.356,50$ & 41,76 \\
\hline
\end{tabular}

As equações que melhor se ajustaram aos dados experimentais obtidos para as propriedades físicas, das cultivares Zélia e CMS 43, em função do teor de umidade, são do tipo polinômio de terceiro grau:

$$
\mathrm{Y}=\mathrm{a}+\mathrm{b} \cdot \mathrm{U}+\mathrm{c} \cdot \mathrm{U}^{2}+\mathrm{d} \cdot \mathrm{U}^{3}
$$

em que:

$\mathrm{Y}$ - massa específica aparente $\left(\mathrm{kg} \mathrm{m}^{-3}\right)$ e massa específica unitária

$\left(\mathrm{kg} \mathrm{m}^{-3}\right)$ ou porosidade da massa granular $(\%)$

$\mathrm{U}$ - teor de umidade do produto (\% b.u.)

a, b, c, d - parâmetros de regressão

Os coeficientes de regressão para a Eq (2) ajustada aos dados experimentais e os coeficientes de determinação $\left(R^{2}\right)$ encontramse na Tabela 2.

Tabela 3. Os parâmetros a, b, c e d e coeficientes de determinação $\left(\mathrm{R}^{2}\right)$ para a Equação (2), obtidas para ambas as cultivares, em

\begin{tabular}{|c|c|c|c|c|c|}
\hline Cultivar & $\mathrm{a}$ & $\mathrm{b}$ & $\mathrm{c}$ & d & $\mathrm{R}^{2}$ \\
\hline \multicolumn{6}{|c|}{ Massa específica aparente $\left(\rho_{\mathrm{Ap}}\right)$} \\
\hline Zélia & 1614,8 & $-182,6$ & 13,1 & $-0,3$ & 0,99 \\
\hline CMS 43 & 1399,8 & $-129,9$ & 9,0 & $-0,2$ & 0,99 \\
\hline \multicolumn{6}{|c|}{ Massa específica unitária $\left(\rho_{\mathrm{Ap}}\right)$} \\
\hline Zélia & 2145,7 & $-194,4$ & 13,8 & $-0,3$ & 0,99 \\
\hline CMS 43 & 2059,3 & $-146,3$ & 10,0 & $-0,2$ & 0,99 \\
\hline \multicolumn{6}{|c|}{ Porosidade da massa granular $(\varepsilon)$} \\
\hline Zélia & 15,3 & 5,0 & $-0,4$ & 0,0 & 0,99 \\
\hline CMS 43 & 16,4 & 5,5 & $-0,4$ & 91,6 & 0,99 \\
\hline
\end{tabular}
função do teor de umidade

Esses resultados estão de acordo com os encontrados por Moraes Neto (1991) para comportamento das variáveis massa específica (aparente e unitária) e porosidade da massa granular, em função do teor de umidade. O modelo cúbico que representa a porosidade da massa granular, está de acordo também com o publicado pela ASAE Standards(1998). 
Os resultados obtidos para variação da massa específica unitária, da porosidade da massa granular e da massa específica aparente em função do teor de umidade, estão de acordo com o esperado, uma vez que apresentaram a mesma tendência da maioria dos grãos agrícolas.

\section{CONCLUSÕES}

Nas condições em que o trabalho foi conduzido e pelos resultados obtidos, conclui-se que:

1. A variação das propriedades físicas dos grãos de milhopipoca, em função do teor de umidade, apresenta a mesma tendência verificada na maioria dos grãos agrícolas.

2. A massa específica aparente e a massa específica unitária do milho-pipoca, de ambas as cultivares, diminuem com o aumento do teor de umidade dos grãos, sendo a equação polinomial de $3^{-}$grau a que melhor se ajustou aos dados experimentais.

3. A porosidade da massa granular do milho-pipoca, das duas cultivares, aumenta com o aumento do teor de umidade dos grãos, sendo a equação polinomial de $3^{\circ}$ grau a que melhor se ajustou aos dados experimentais.

4. Os valores de massa específica (aparente e unitária) e de porosidade da massa granular diferiram entre as cultivares utilizadas, sendo os valores da cultivar CMS 43 sempre superiores aos da cultivar Zélia, podendo esta diferença influenciar na capacidade de expansão.

\section{AGRADECIMENTOS}

Os autores agradecem à Fundação de Amparo à Pesquisa do Estado de Minas Gerais - FAPEMIG, e ao Conselho Nacional de Desenvolvimento Científico e Tecnológico - CNPq, pelo apoio financeiro para a realização deste trabalho.

\section{REFERÊNCIAS BIBLIOGRÁFICAS}

ASAE STANDARDS 1998: Standards, engineering practices and data. 45 ed. ASAE, St. Joseph,1998. 978p.

CHUNG, D.S.; CONVERSE, H.H. Effect of moisture content on some physical properties of grains. Transactions of the ASAE, St.Joseph, v.69, n.1, p.811, 1969.

DALBELLO, O.; BIAGI, J.D. Influência do teor de umidade, tamanho e massa específica dos grãos na capacidade de expansão do milho-pipoca (Zea mays). In: CONGRESSO BRASILEIRO DE ENGENHARIA AGRÍCOLA, 25, 1996, Bauru. Anais... Bauru: Universidade Estadual de São Paulo. (CD-ROM).

GUSTAFSON, R.J.; HALL, G.E. Density and porosity changes of shelled corn during drying. Transactions of the ASAE, St.Joseph, v.15, n.1, p.523-525, 1972.

LYERLY, P.J. Some genetic and morphologic characters affecting the popping expansion of popcorn. Journal of the American Society of Agronomy, Madison, v.34, n.11, p.986-999, 1942.

INFORMATIVO COOPERCITRUS. Milho-pipoca: cultura tem tudo para expandir-se. São Paulo, n.78, p.8-11, 1993.

MORAES NETO, J.M. Determinação de parâmetros básicos de feijão carioquinha necessários ao modelamento matemático de secagem em camada espessa. Campina Grande, PB: UFPB, 102p. Dissertação Mestrado.

PACHECO, C.A.P.; CASTOLDI, F.L.; ALVERENGA, E.M. Efeito do dano mecânico na qualidade fisiológica e na capacidade de expansão de sementes de milho-pipoca. Revista Brasileira de Sementes, Campinas, v.18, n.2, p.267-270, 1996.

SILVA, W.J. Estudo amplia pesquisa de milho. Jornal da UNICAMP, Campinas, maio, 1993. p.8.

SONG, A.; ECKHOFF, S.R. Optimum popping moisture content for popcorn kernels of different sizes. Cereal Chemistry, St. Paul, v.71, n.5, p.458-460, 1994.

WHITE, G.M.; ROSS I.J.; PONELEIT, C.G. Influence of drying parameters on the expansion volume of popcorn. Transactions of the ASAE, St. Joseph, v.23, n.5, p.1272-1276, 1980. 